\title{
ELEMENTOS PARA UMA TEORIA DO CONHECIMENTO EM MATÉRIA E MEMÓRIA
}

\section{FERNANDO MONEGALHA ${ }^{1}$}

RESUMO: Embora Bergson não consagre nenhuma obra específica à elaboração de uma teoria do conhecimento, encontramos elementos esparsos ao longo de várias de suas obras que podem nos ajudar a elaborar o que seria uma teoria do conhecimento bergoniana. Neste artigo, buscamos trabalhar tais elementos em Matéria e Memória, principalmente a partir de seus dois capítulos centrais, onde Bergson se propõe a discutir o modo de formação tanto de nossas percepções concretas quanto de nossas ideias gerais. Como veremos, para Bergson ambos os processos estão estritamente vinculados à sua teoria dos graus de duração, onde a ideia de uma rememoração incessante do passado ocupa um lugar central.

PALAVRAS-CHAVE: Bergson; Teoria do conhecimento; Graus de duração.

ABSTRACT: Although Bergson does not devote any specific work to the elaboration of a theory of knowledge, we find scattered elements throughout several of his works that can help us to elaborate what could be a Bergsonian theory of knowledge. In this article, we seek to work on these elements in Matter and Memory, mainly from its two central chapters, where Bergson discusses the way both our concrete perceptions and our general ideas are formed. As we shall see, for Bergson both processes are strictly linked to his theory of degrees of duration, where the idea of an incessant remembrance of the past occupies a central place.

KEYWORDS: Bergson; Theory of knowledge, Degrees of duration.

\section{Introdução}

Que o problema mais geral de Matéria e memória seja o da relação mente-corpo, é algo que o próprio subtítulo da obra ("Ensaio sobre a relação do corpo com o espírito") já nos informa de modo bastante incisivo. Ainda assim, tratando-se de uma obra monumental e quase infindável, é inevitável que encontremos em Matéria e memória toda uma diversidade de temas que extrapolam o âmbito da discussão estrita da relação mente-corpo, e que constituem parte da riqueza quase inesgotável dessa obra. Um desses temas, que encontramos no livro (e em artigos posteriores, tal como $O$ esforço intelectual) é o esboço, por parte de Bergson, de uma incipiente teoria do conhecimento, baseada em sua ideia de uma diversidade

\footnotetext{
${ }^{1}$ Professor Adjunto de Filosofia pela Universidade Federal de Alagoas (UFAL). Doutor em Filosofia pela Universidade Federal de São Carlos (UFSCar). E-mail: fmonegalha@uol.com.br.
} 
de planos de consciência ou de graus de duração ${ }^{2}$. O que nos propomos a fazer neste artigo é retraçar os contornos mais gerais dessa teoria, no que tange aos seus dois aspectos essenciais, a saber, a explicação da formação de nossas percepções concretas (no segundo capítulo do livro) e a formação das ideias gerais (no terceiro capítulo). Antes, contudo, de entrar no âmbito mais estrito de nossa discussão, cabe fazer algumas pontuações sobre a constituição da memória espontânea para Bergson, pois será ela a chave explicativa que o autor utilizará para explicar os dois processos em pauta. Com efeito, é a partir da tese de uma contração ou retenção quase ilimitada de nosso passado que Bergson poderá propor sua teoria dos graus de duração, a qual estará na base de todo esse esboço de teoria do conhecimento presente em Matéria e memória. Passemos, portanto, a uma breve discussão sobre o modo de constituição de nosso passado em Bergson, antes de adentrarmos em sua teoria do conhecimento propriamente dita.

\title{
1. A memória espontânea: a contração incessante do passado
}

A memória e a consciência têm uma vinculação bastante estreita para Bergson. Como lemos a esse respeito numa famosa passagem de $A$ consciência e a vida:

\begin{abstract}
Consciência significa primeiramente memória. A memória pode ter pouca amplitude; pode não abarcar mais do que uma pequena parte do passado; pode não reter mais do que aquilo que acaba de acontecer; mas a memória está aí, ou então a consciência não está. Uma consciência que nada conservasse de seu passado, que incessantemente esquecesse de si mesma, pereceria e renasceria a cada instante: como definir de outro modo a inconsciência? [...] Portanto, toda consciência é memória - conservação e acumulação do passado no presente. (BERGSON, 2009, p. $5)$.
\end{abstract}

"Consciência significa primeiramente memória" - o que isto significa? Primeiramente, que todo estado consciente envolve sempre a retenção ou contração contínua do passado no presente. Para compreendermos o que significa tal contração ou retenção, podemos nos ater ao arquetípico exemplo de uma melodia: toda melodia envolve uma retenção contínua das notas precedentes na nota que atualmente ouvimos - é essa retenção que nos dá o todo melódico propriamente dito, sem ela nós teríamos simplesmente a nota atual cercada de vazio e de silêncio. Ora, aquilo que se passa para Bergson no interior de uma melodia se processa, para ele, igualmente em todo estado consciente: não há, com efeito, para ele, nenhum vivido

\footnotetext{
${ }^{2}$ Ressaltemos que a presença de uma teoria do conhecimento em Matéria e memória foi algo bem pontuado por Frédéric Worms em Introduction a Matière et mémoire, que tem um primeiro capítulo intitulado justamente "Une théorie de La connaissance fondée sur l'action". (WORMS, 1997).
} 
psicológico que se furte a essa "conservação e acumulação" incessante do passado no presente. Isso equivale a dizer que todo estado consciente envolve necessariamente uma duração determinada (a ideia de retenção ou contração nos dá, com efeito, o significado primordial da duração bergsoniana). Quando eu tenho uma sensação visual simples, quando eu sinto uma dor, quando tenho uma emoção muito forte, quando uno conceitos num juízo em todos estes casos eu verifico que a conservação do passado no presente é uma condição necessária para a existência do estado consciente em questão. Mas falar de conservação do passado no presente é a mesma coisa que falar de memória, logo, a memória é a responsável pela existência de qualquer estado consciente. Nesse sentido, a memória é algo de uma importância muito maior do que suspeitou a tradição filosófica: ela não é uma faculdade entre as demais faculdades, mas a condição de possibilidade de todas as faculdades, algo psicologicamente (e ontologicamente) primordial. Poderíamos dizer que é ela quem torna a consciência possível, mas, de fato, seu exercício se confunde com o da própria consciência: estar consciente, para Bergson, equivale a estar contraindo o passado no presente, logo, falar de consciência equivale a falar de memória, não há uma decalagem ou uma diferença radical entre ambas.

Todo estado consciente envolve então a memória. Mas até onde se estende o exercício da memória? Até agora tratamos de estados conscientes relativamente efêmeros: uma melodia, uma sensação, uma dor, etc. Mas, de fato, para Bergson, é a totalidade de nosso passado que está sendo contraída constantemente no presente: contraímos, efetivamente, tudo aquilo que se passou em nosso passado no momento atual de nossa consciência - é isso que define nossa personalidade ou nosso caráter. Bergson, com efeito, define em Matéria e memória o caráter como sendo "a síntese atual de todos os nossos estados passados" (BERGSON, 1999, p. 170). Novamente, não se trata de dizer aqui que o caráter e a consciência sejam radicalmente diferentes, mas que ambos se confundem, na medida em que a consciência implica uma totalização retencional contínua de tudo aquilo que sentimos, vivemos e pensamos. Nesse sentido, é toda nossa vida consciente que corresponde, para Bergson, à existência de uma grande melodia: com efeito, assim como a melodia é formada pela contração das notas precedentes na nota atual, assim a nossa consciência pessoal é formada, para Bergson, pela contração contínua de tudo aquilo que vivenciamos desde nosso nascimento até o dia de hoje. A esse respeito, bastaria que apenas um único momento precedente de nossa vida tivesse sido diferente para que nós fôssemos efetivamente diferentes do que somos hoje. Como diz a esse respeito Bergson, "Vocês não poderiam diminuir nem de 
um único instante a vida psicológica sem lhe modificar o conteúdo. Acaso se pode, sem desnaturá-la, encurtar a duração de uma melodia? A vida interior é exatamente essa melodia" (BERGSON, 2006, p. 11/13).

Ao lado de nossos estados conscientes mais efêmeros (tal como a audição de uma melodia, por exemplo), nós temos, portanto, a grande melodia de nossa vida consciente, a totalização retencional contínua de tudo aquilo que sentimos, vivemos e pensamos. Bem pensado, é essa ideia da consciência como grande melodia que está por detrás da caracterização da memória espontânea que nos fornece Bergson em Matéria e memória: "Coextensiva à consciência, ela retém e alinha uns após outros todos os nossos estados à medida que eles se produzem, dando a cada fato seu lugar e consequentemente marcando-lhe a data" (BERGSON, 1999, p. 177). Há, portanto, uma memória fundamental para Bergson, que é aquela que retém continuamente o passado no presente, desde o nosso nascimento até os dias atuais, memória essa cujo exercício se confunde com o processo de constituição de nossa própria vida consciente.

Mas aqui devemos fazer uma ressalva. Se é verdade que a memória espontânea se confunde com a grande melodia da nossa vida consciente, isso não equivale a dizer, contudo, que estejamos conscientes de tudo aquilo que ocorreu em nosso passado. Como se sabe, uma das teses mais marcantes de Matéria e memória consiste precisamente na afirmação de que a maior parte de nosso passado permanece em nossa memória num estado inconsciente, puramente virtual. De fato, assim como não estamos conscientes de todas as notas que compõem uma melodia (já que estas coexistem umas com as outras num estado confuso, numa multiplicidade qualitativa indistinta), assim tampouco estamos conscientes de todos os fatos que ocorreram em nosso passado, e que se encontram fundidos e amalgamados nessa grande melodia que compõe nossa personalidade. Desse modo, para que nós atualizemos nosso passado, é necessário um esforço de rememoração, que fará com que o passado passe de seu estado tão-somente virtual a um estado atual, o que equivale a dizer, que as lembranças que se encontram num estado "puro" (como gosta de dizer Bergson) adquiram um estatuto imagético, advindo "lembranças-imagem" (ou seja, a lembrança tal como aparece para nós ao ser rememorada). Em Matéria e memória, Bergson compara esse processo de rememoração ao ajuste de foco de uma máquina fotográfica:

Trata-se de recuperar uma lembrança, de evocar um período de nossa história? Temos consciência de um ato sui generis pelo qual deixamos o presente para nos recolocar primeiramente no passado em geral, e depois numa certa região do passado: trabalho de tentativa, semelhante à busca do foco de uma máquina 
fotográfica. Mas nossa lembrança permanece ainda em estado virtual; dispomo-nos simplesmente a recebê-la, adotando a atitude apropriada. Pouco a pouco aparece como que uma nebulosidade que se condensasse; de virtual, ela passa ao estado atual, e, à medida que seus contornos se desenham e sua superfície se colore, ela tende a imitar a percepção. (BERGSON, 1999, p. 156).

De um lado, temos, portanto, a retenção/contração contínua do passado no presente, nessa grande totalidade retencional que é a nossa personalidade ou nosso caráter, de outro a rememoração do passado, que faz com que o passado passe de seu estado virtual e inconsciente a um estado atual. Como veremos, será basicamente esse jogo entre a retenção e a rememoração do passado que estará em operação na teoria do conhecimento que Bergson esboça nos capítulos centrais de Matéria e memória.

\section{A formação da percepção concreta}

Fechado esse parêntese inicial sobre o papel de nossa memória, procuremos então entender primeiramente o papel que o passado desempenha na formação de nossas percepções concretas. Para isso, retomemos a distinção que fizéramos anteriormente entre a retenção e a rememoração do passado. Como dizíamos, para Bergson nosso passado individual se constitui por meio da retenção contínua de tudo aquilo que vivemos, sentimos e pensamos. Nesse sentido, o termo "passado" não significa nada além da contração de todas as nossas vivências em nossa consciência, a qual se constitui ao modo de uma grande melodia, ou seja, como uma grande totalidade retencional. É por meio deste processo de retenção do passado que se dá a formação de nossas lembranças, as quais se encontram para Bergson todas contraídas em nossa consciência, fundidas aí de tal modo que não podemos ter uma visão clara de cada uma delas em sua individualidade, o que é a mesma coisa que dizer que elas se encontram aí num estado tão somente virtual ou inconsciente ${ }^{3}$. A rememoração, por sua vez,

\footnotetext{
3 Alguém poderia se indagar como algo pode fazer parte de nossa consciência e ser ao mesmo tempo um conteúdo inconsciente. A resposta, cremos nós, pode ser encontrada na teoria das multiplicidades bergsoniana: enquanto fazem parte dessa grande totalidade retencional que é nossa consciência imediata, as lembranças permanecem num tal estado de fusão e interpenetração recíproca que é impossível distinguir uma delas da totalidade da qual fazem parte. É como no caso da melodia: nós não temos consciência das notas individuais que fazem parte dela, mas tão-somente da totalidade melódica que elas compõem. Assim, nós não temos consciência das lembranças individuais que compõem a grande melodia de nossa vida interior, mas somente da síntese de tais lembranças, as quais compõem a nossa personalidade e nosso caráter. Que o passado não seja algo substancialmente diferente da própria consciência, é algo que Bergson deixa bem claro na seguinte passagem: "Nossa vida interior inteira é algo como uma frase única iniciada já no primeiro despertar da consciência, frase cheia de vírgulas, mas em parte alguma interrompida por pontos. Consequentemente, acredito que nosso passado inteiro está aí, subconsciente - quero dizer, presente em nós de tal modo que, para obter sua revelação, nossa consciência não precise sair de si mesma nem acrescer-se de nada externo: para perceber distintamente tudo o
} 
implica um trabalho inverso ao de retenção, pois ela consiste na localização de uma lembrança específica no passado virtual. Anteriormente, vimos que Bergson comparava o esforço rememorativo ao ajuste de foco de uma máquina fotográfica, onde primeiramente nos instalamos numa "nebulosidade vaga" (a totalidade das lembranças contraídas em nosso passado), para pouco a pouco extrair dessa nebulosidade uma lembrança específica, que adquirirá uma existência imagética conforme ela passe de seu estado virtual para se aproximar do modo de ser de nossa percepção, tornando-se aquilo que Bergson denomina uma “lembrança-imagem”. É por meio do esforço rememorativo que se dá, portanto, o processo de atualização do passado para Bergson.

Poderíamos pensar, a partir de exemplos como o acima citado, que o passado é rememorado somente de forma ocasional, a saber, quando nos dispomos, por meio de um esforço voluntário, a buscar uma determinada lembrança específica. Mas esse está bem longe de ser o caso, já que o passado está sendo rememorado o tempo todo para Bergson, mas de um modo, na maior parte das vezes, involuntário. Nesse sentido, podemos dizer que não há nenhum momento de nossa vida espiritual em que o passado não esteja se materializando no presente, em que o virtual não esteja a se atualizar. Para compreendermos um pouco melhor como se dá este processo de atualização constante do passado, deter-nos-emos em algumas passagens de fundamental importância do segundo capítulo de Matéria e memória, no qual Bergson busca determinar o modo como as lembranças puras influem continuamente na constituição de nossas percepções concretas.

Bergson inicia este capítulo de sua obra fazendo uma distinção de fundamental importância entre dois tipos de memória, a saber, a memória espontânea e a memória-hábito. A memória espontânea, da qual já falamos anteriormente, consiste basicamente na contração ininterrupta do passado realizada por nossa consciência ao longo de nossa vida subjetiva. Já a memória-hábito é de uma natureza bem diferente: estritamente vinculada ao nosso corpo, ela consiste num conjunto de mecanismos motores montados para agir de forma idêntica em determinadas circunstâncias, sendo adquirida pela repetição constante de certos movimentos e ações corporais. Bergson afirmará que a diferença entre ambas as memórias é radical, pois se trata de uma diferença de natureza, e não apenas de grau. Há uma diferença de natureza entre ambas, já que uma memória é espiritual, e a outra é corporal; uma se atualiza num conjunto de representações imaginadas por nós, enquanto a outra se atualiza sob a forma de determinadas

que contém em si, ou melhor, tudo aquilo que é, tem apenas de afastar um obstáculo, de levantar um véu." (BERGSON, 2009, p. 56) 
ações corporais, que podem perfeitamente prescindir de toda representação consciente, desenvolvendo-se de forma quase automática.

A fim de ilustrar essa diferença entre a memória espontânea e a memória-hábito, Bergson toma o exemplo da memorização de um texto. Segundo ele, o esforço empreendido para saber um texto de cor é claramente algo pertencente à esfera da memória-hábito, visto que isso consiste num trabalho maquinal e repetitivo, que visa construir um conjunto de ações corporais bem determinadas, decorrendo disso que possamos recitar um texto, depois de memorizado, de modo quase automático. Bem diferente seria, contudo, se tentássemos nos lembrar de uma ocasião específica em que nós recitamos um texto (em um casamento, por exemplo); neste caso, seria a memória espontânea, e não a habitual, que entraria em jogo, pois se trataria de buscar uma lembrança específica em meio à totalidade de nosso passado individual, atualizando essa lembrança específica numa representação imagética. Uma memória, portanto, atualiza o passado por meio de um trabalho da imaginação, ao passo que a outra o repete por meio de um conjunto de esquemas motores montados em nosso organismo. Se a memória-hábito consiste na pura repetição de nossas ações corporais passadas, as lembranças contraídas na memória espontânea dizem respeito àquilo que, por definição, não pode se repetir, pois cada uma delas corresponde a um acontecimento singular, completamente diferente de todos os demais que compõem a integralidade de nosso passado.

Dizíamos anteriormente que a rememoração não se restringia aos casos de evocação voluntária do passado; é necessário agora precisar o que isso significa. Para Bergson, o passado não está sendo atualizado apenas nos casos em que evocamos uma lembrança de nosso passado, mas em todo momento em que se opere algum tipo de reconhecimento de um objeto que nos é presente. De fato, há para Bergson uma estrita correlação entre a memória e o reconhecimento, na medida em que o reconhecimento é "o ato concreto pelo qual reavemos o passado no presente" (BERGSON, 1999, p. 99). E do mesmo modo que existem dois tipos de memória para Bergson, há dois tipos de reconhecimento bem distintos para ele, um habitual e corporal, e o outro espiritual e atento. Bergson cita como exemplo de reconhecimento habitual o de um sujeito que caminha maquinalmente pelas ruas de uma cidade, movido apenas pela força do hábito. Neste caso específico, notamos que seu corpo executa um conjunto de ações que foram reforçados por repetições anteriores, reagindo de modo automático ou quase automático a certo conjunto de estímulos, o que lhe permite orientar-se pela cidade sem que seja necessária a intervenção de nenhuma atividade consciente; ele simplesmente se move pelas ruas desta cidade sem ter de pensar em nenhum 
momento qual será o caminho que deverá seguir. Neste exemplo, vemos bem claramente que o reconhecimento habitual é um reconhecimento especificamente corporal, que não envolve nenhum ato espiritual por parte do indivíduo. Bem diferente do reconhecimento habitual, contudo, é o reconhecimento espiritual, que Bergson também denomina reconhecimento atento. Neste caso, o sujeito reconhece um determinado objeto como sendo idêntico ou semelhante a outro objeto que ele conheceu no passado. É o caso, por exemplo, de quando identificamos uma determinada pessoa ou objeto que aparece em nosso campo perceptivo, ou de quando efetuamos a leitura atenta de um texto, interpretando-o a partir de nossa experiência passada. Em todos estes casos, vemos que o espírito recorre constantemente às lembranças contraídas em sua memória espontânea, a fim de permitir que sua experiência pretérita possa aclarar o presente. A importância do reconhecimento atento reside, para Bergson, no fato de ser por meio dele que as lembranças puras majoritariamente se atualizam, deixando seu estatuto inicialmente inconsciente para progressivamente se converterem em lembranças-imagens, as quais terão como destino final a integração à percepção consciente. Ou seja, é por meio do reconhecimento atento que o passado se atualiza no presente.

Como se dá este processo de atualização do passado? O reconhecimento atento inclui, como o próprio nome indica, um ato de atenção do espírito. Para Bergson, uma propriedade bem clara do processo de atenção é o fato de ele enriquecer progressivamente o objeto por nós percebido: pela atenção, nós descobrimos uma variedade de detalhes num mesmo objeto que antes não havíamos observado, para os quais antes não havíamos atentado. Para Bergson, este progressivo enriquecimento do objeto no qual prestamos atenção indica um trabalho mais profundo da memória, por meio do qual ela projeta progressivamente lembranças em nosso campo perceptivo, dotando o objeto percebido de uma riqueza e individualidade superiores. Para ilustrar esse ponto, Bergson recorre às experiências sobre o mecanismo da leitura efetuadas por Goldscheider e Müller, que mostravam já naquela época que a leitura de uma palavra nunca é feita letra por letra, mas por meio de grandes pulos e saltos, que tornam a leitura corrente "um verdadeiro trabalho de adivinhação" (BERGSON, 1999, p. 117).

Para Bergson, esses experimentos são indicativos de que retemos de uma palavra somente alguns "traços característicos", todo o restante sendo fruto de um trabalho de projeção das lembranças-imagens sobre nosso campo perceptivo, "lembranças-imagens que, projetadas sobre o papel, substituem-se aos caracteres realmente impressos e nos dão sua ilusão" (BERGSON, 1999, p. 117). Nesse caso, percebemos com clareza como a memória 
intervém continuamente sobre nossa percepção de objetos, acrescentando elementos que não constavam dela originalmente. Como veremos mais adiante, para Bergson nossa percepção de objetos é de início bastante vaga e geral, e somente pela intervenção da memória essa percepção vaga pode adquirir uma individualidade superior, advindo uma percepção de objetos distintos. Na verdade, para Bergson, nossa percepção seria algo extremamente empobrecido sem o auxílio da memória, que desempenha um papel de fundamental importância na nossa apreensão dos objetos. Basta dizer aqui que é a memória que dota os objetos por nós percebidos de um sentido específico, sem o qual eles se reduziriam, para nós, à materialidade sensível bruta que apreendemos por meio de nosso corpo. Em relação à percepção, a memória não é, portanto, algo secundário, uma faculdade que simplesmente recolheria as imagens particulares por nós percebidas, mas sim algo primário, na medida em que ela opera no próprio processo de constituição dos objetos por nós apreendidos. Como Bergson afirma num texto que teremos a oportunidade de retomar mais adiante,

\begin{abstract}
seria enganar-se extremamente aqui sobre o mecanismo do reconhecimento acreditar que começamos por ver e ouvir e que em seguida, uma vez constituída a percepção, aproximamo-la de uma lembrança semelhante para reconhecê-la. Na verdade, é a lembrança que nos faz ver e ouvir, e a percepção seria incapaz, por si só, de evocar a lembrança que se assemelha a ela, visto que para isso seria preciso que já tivesse tomado forma e estivesse suficientemente completa; ora, ela só se torna percepção completa e só adquire uma forma distinta graças justamente à lembrança, que se insinua nela e lhe fornece a maior parte de sua matéria. Mas, se é assim, é preciso que seja o sentido, antes de tudo, que nos guie na reconstituição das formas e dos sons. (BERGSON, 2009, p. 170-1).
\end{abstract}

Esse processo constante de projeção do passado sobre o presente nos indica que o virtual está sempre se atualizando, não para nunca de se atualizar. Na verdade, todo objeto real percebido por nós nunca é algo simplesmente atual, pois nele há sempre uma contraparte virtual, que não é nada mais que as lembranças que projetamos sobre ele, a fim de dotá-lo de um sentido. É preciso acrescentar que este processo de projeção do passado sobre o presente não é um processo linear ou horizontal, mas algo relativamente complexo, que envolve diversos níveis de complicação do espírito. Para Bergson um mesmo objeto pode ser percebido por nós em diversos níveis de generalidade ou particularidade, e isso é indicativo que diferentes esforços de memória estão se processando em cada caso. Por exemplo: ao mirar um determinado papel com um texto que se encontra à minha frente, eu posso ter diferentes tipos de reconhecimento deste mesmo objeto. Em princípio, esse papel pode aparecer para mim em sua mais simples materialidade sensível, a saber, como um determinado conjunto de manchas negras contrapostas ao simples fundo branco do papel. Com um pouco mais de atenção, contudo, eu posso reconhecer que há um conjunto de 
caracteres nesse papel e me dar conta que se trata de um texto. Ao pegar o papel em mãos e confrontá-lo com um pouco mais de atenção, eu posso verificar que se trata de uma poesia. Por fim, ao lê-la com atenção, verifico que essa poesia é algo já conhecido por mim - eu constato, por exemplo, que a tal poesia é "Tabacaria" de Álvaro de Campos, que eu li em meu passado recente ou remoto. Em todos esses casos, verificamos que o mesmo objeto, por um esforço variado de atenção, pode ser percebido de formas variadas. Para Bergson, o que está ocorrendo aqui é uma variação no trabalho subterrâneo da memória, que se comporta diferentemente em cada um destes casos, projetando um tipo de lembrança específico para cada um dos casos acima. Neste processo, "criamos ou reconstruímos a todo instante" (BERGSON, 1999, p. 117) o objeto de nossa percepção, dependendo do tipo de lembrança que é projetado sobre nosso campo perceptivo. Para explicar essa diversidade de formas que o objeto pode assumir, Bergson afirmará que nossa memória não se desenvolve num único plano, mas que há uma diversidade de níveis possíveis de expansão ou contração $o^{4}$ da memória, responsáveis pela forma diferenciada que o objeto de nossa percepção assume. Para ilustrar essa diversidade de níveis da memória, ele propõe um gráfico sob a forma de um circuito elétrico, o qual reproduzimos abaixo:

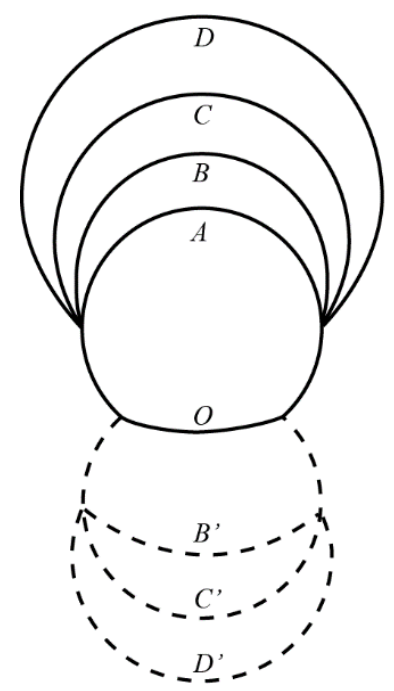

Figura 1 - O reconhecimento atento

4É importante distinguir os dois usos do termo "contração" em Bergson: uma coisa é a contração do passado enquanto um sinônimo de retenção, que é o uso que temos empregado até o presente momento, outra coisa a contração do passado no âmbito da rememoração, que basicamente indica o processo por meio do qual diversas lembranças rememoradas por nós se fundem e se interpenetram num gênero ou espécie mais geral. 
Procuremos interpretar esse gráfico, que está bem longe de ser evidente. Nele, temos inicialmente o objeto $\mathrm{O}$ de nossa percepção imediata, acrescido de "diferentes círculos da memória" (BERGSON, 1999, p. 119), que correspondem aos círculos concêntricos A, B, C e D na parte superior do gráfico. Por meio destes círculos, Bergson figura "esforços crescentes de expansão intelectual" (id.), isto é, diferentes graus de expansão e contração da memória. Mas o que isso significa exatamente? Para compreendê-lo, recapitulemos alguns elementos anteriores. Como vimos, para Bergson nossa consciência retém todos os detalhes de nossa vida pretérita, tudo aquilo que vivemos, pensamos e sentimos. Se pudéssemos atualizar a totalidade de nossa memória espontânea (o que não é possível), veríamos toda nossa vida pretérita se desenrolar em seus detalhes os mais ínfimos, em sua mais completa particularidade. No caso de nosso exemplo anterior, lembrar-nos-íamos de cada texto lido por nós, de cada poesia que lemos ao longo de nossa vida, acrescentada da circunstância em que travamos contato com ela. Eu me lembraria, por exemplo, de ter lido "Tabacaria" em tal dia e tal horário, além de me recordar do sentimento específico que esta leitura me provocou. Nesse caso específico, estaríamos posicionados, segundo Bergson, no círculo mais excêntrico da memória, aquele que abarca a totalidade de nossas lembranças individuais: "as lembranças pessoais, exatamente localizadas, e cuja série desenharia o curso de nossa existência passada, constituem o último e maior invólucro de nossa memória” (BERGSON, 1999, p. 120). É esse invólucro que é ilustrado pelo círculo mais excêntrico do gráfico acima.

Ocorre que, para Bergson, a nossa memória também pode se simplificar, repetindo-se em círculos em que ela assume uma forma cada vez mais ordinária e reduzida:

Mas esse invólucro extremo se comprime e se repete em círculos interiores e concêntricos, os quais, mais restritos, contêm as mesmas lembranças diminuídas, cada vez mais afastadas de sua forma pessoal e original, cada vez mais capazes, em sua banalidade, de se aplicar à percepção presente e de determiná-la à maneira de uma espécie englobando o indivíduo. (BERGSON, 1999, p. 120-1).

Para compreender este ponto, podemos pensar em nosso exemplo anterior: se, ao me situar no círculo mais excêntrico da memória, recordo-me de uma lembrança absolutamente particularizada ("Tabacaria", por ex.), nos círculos mais concêntricos a individualidade da lembrança se apaga para dar lugar a espécies cada vez mais genéricas (não "Tabacaria", mas um poema em geral, ou mesmo um simples texto). Deste modo, passamos gradualmente do círculo mais excêntrico da memória, em que as lembranças se encontram completamente particularizadas, a círculos mais concêntricos, em que diversas lembranças semelhantes fundem-se entre si assumindo então um grau de generalidade cada vez mais amplo. Por sua 
vez, estas lembranças diferenciadas, no caso do reconhecimento atento, são projetadas em nosso campo perceptivo, fazendo com que o objeto $\mathrm{O}$ de nossa percepção possa assumir diversas feições de acordo com o círculo da memória em que nos situamos. Assim, por exemplo, se em OD o objeto nos aparece de um modo completamente particular ("Tabacaria"), em OC, OB e AO ele assume uma configuração cada vez mais genérica (um poema, um texto ou um mero agregado de sensações) $)^{5}$.

O que o gráfico do reconhecimento atento nos mostra, portanto, é que o objeto de nossa percepção pode assumir um grau maior ou menor de generalidade de acordo com o nível de expansão ou contração da memória que nós atingimos no processo de rememoração do passado. Como veremos a seguir, para Bergson o nosso passado não é repetido num único nível, mas comporta uma enorme variedade de repetições possíveis, de acordo com o grau atingido por nossa consciência em seu esforço de rememoração e reconhecimento. Para designar esse esforço de expansão da memória, Bergson falará de uma tensão maior da consciência; para o filósofo francês, é por um esforço intensivo que nos situamos nos círculos mais excêntricos da memória, onde nosso passado surge para nós em toda a sua riqueza individual. A intensidade designa, portanto, para Bergson, o estágio de expansão e contração da memória atingido no esforço de rememoração do passado.

Podemos sintetizar o que foi dito acima afirmando que, para Bergson, o passado, longe de ser rememorado apenas esporadicamente, é rememorado o tempo todo, na medida em que toda percepção concreta envolve, em maior ou menor grau, um esforço de reconhecimento, logo, de evocação do passado. A rememoração no reconhecimento é, portanto, o modo pelo qual o passado virtual se atualiza constantemente no presente, tudo isso ocorrendo, vale a pena ressaltar, de modo preponderantemente involuntário, já que tal rememoração não surge de nenhum ato deliberado do indivíduo. Por meio desse processo de atualização do passado, o nosso campo perceptivo é reconstruído constantemente, de acordo com o tipo de lembrança que é projetado sobre ele; nesse ínterim, a lembrança pura adquire uma forma cada vez mais imagética, convertendo-se progressivamente numa percepção concreta, aproximando-se assim do modo de ser dos movimentos corporais efetivos. Como veremos logo a seguir, este processo também estará na base da explicação bergsoniana sobre o mecanismo de formação das ideias gerais.

\footnotetext{
${ }^{5}$ Em todos estes casos, é bom ressaltar, é a totalidade da memória que está em jogo para Bergson. "É a totalidade da memória, conforme veremos, que entra em cada um desses círculos, já que a memória está sempre presente; mas essa memória, que sua elasticidade permite dilatar indefinidamente, reflete sobre o objeto um número crescente de coisas sugeridas”. (BERGSON, 1999, p. 119).
} 


\section{A relação mente-corpo}

A análise do reconhecimento atento e do mecanismo da percepção concreta já antecipa aquele que será o núcleo do capítulo III de Matéria e memória (e talvez de toda a obra bergsoniana): a teoria dos graus de duração ou dos planos de consciência ${ }^{6}$. Por meio dessa teoria Bergson buscará determinar as relações gerais entre o espírito e o corpo, assim como estabelecer a estrutura geral do trabalho intelectual. É no capítulo III de Matéria e memória que ele detalhará essa teoria, e é por isso que nos deteremos a partir de agora sobre essa parte de sua obra.

Bergson inicia o capítulo III de Matéria e memória recapitulando as conclusões do capítulo II, lembrando que há uma continuidade entre a lembrança-pura, a lembrança-imagem e a percepção. Como vimos, é através do processo de reflexão das lembranças em nosso campo perceptivo que uma lembrança deixa seu estado inicial puramente virtual para paulatinamente tornar-se algo atual, adquirindo assim uma existência imagética que a aproxima do modo de ser de nossos estados corporais. Ocorre que, apesar dessa continuidade entre as lembranças e as percepções, ainda parece haver uma dualidade intransponível entre o corpo e o espírito no esquema bergsoniano, pois os hábitos corporais e a memória espontânea correspondem para ele a dois tipos de memória mutuamente excludentes. Cabe ressaltar que, no caso dos hábitos corporais, estamos lidando para Bergson com um conjunto de ações corporais eminentemente atuais, que se desenvolvem no presente e que ocupam certa extensão espacial, enquanto no segundo caso (memória espontânea), lidamos com um conjunto de lembranças que têm um caráter eminentemente virtual, que se situam no passado puro e que são absolutamente inextensas. Ora, já que a determinação de ambas as memórias envolve predicados opostos, haveria então uma oposição radical entre elas, o que parece levar ao estabelecimento de um dualismo intransponível entre o corpo e o espírito.

Mas esse dualismo é insuperável somente à primeira vista. Como Bergson não tarda a esclarecer, devemos ter em vista aqui que nosso corpo já possui uma temporalidade nuclear, que lhe permite contrair seu passado imediato. De fato, como Bergson explica no terceiro capítulo de Matéria e memória, o presente corporal concreto consiste num pequeno campo temporal sensório-motor, no qual o lado "sensório" indica exatamente essa capacidade do

\footnotetext{
${ }^{6}$ Como Frédéric Worms nos lembra (WORMS, 1997B, p. 85-6), era o próprio Bergson quem colocava a teoria dos graus de duração como "ponto de partida" ou "ideia diretriz" de seu trabalho intelectual em Matéria e memória: "Há portanto, enfim, tons diferentes de vida mental, e nossa vida psicológica pode se manifestar em alturas diferentes, ora mais perto, ora mais distante da ação, conforme o grau de nossa atenção à vida. Esta é uma das ideias diretrizes da presente obra, a própria ideia que serviu de ponto de partida para nosso trabalho". (BERGSON, 1999, p. 7).
} 
organismo de reter seu passado imediato sob a forma de sensações elementares. Deste modo, assim como podemos afirmar que o corpo constitui o próprio presente concreto de nossa existência, também podemos afirmar que "nunca percebemos outra coisa que não nosso passado imediato" (BERGSON, 1999, p. 177), uma vez que qualquer sensação corporal é constituída de uma duração mínima, na qual se dá a contração do passado imediato de um organismo. Ou seja, assim como nossa consciência contrai todo o seu passado individual no presente, assim também o nosso corpo contrai o seu passado imediato sob a forma de sensações elementares, do modo análogo ao que faz a nossa consciência. Sob este novo ponto de vista, podemos dizer que há, entre a memória espontânea e a memória-hábito de nosso corpo, uma simples diferença de grau, e não mais de natureza. Deste modo, as duas memórias que havíamos distinguido anteriormente "irão fundir-se intimamente" (BERGSON, 1999, p. 177).

A temporalidade do corpo explica, portanto, como a lembrança pura pode advir progressivamente uma imagem, uma sensação; isso ocorre porque nosso corpo, por possuir uma duração mínima, já é memória para Bergson ${ }^{7}$. Ele é o grau mais baixo de nossa memória, "uma memória quase instantânea, à qual a verdadeira memória do passado serve de base" (BERGSON, 1999, p. 178). Isso nos ajuda a compreender melhor o gráfico do cone que Bergson nos apresenta em Matéria e memória: o que ele nos mostra é a relação interna entre as duas memórias que discriminamos antes - a espontânea e a habitual -, ou seja, a relação interna entre esses dois graus diversos de duração que constituem, de um lado, a integralidade de nosso passado individual (retido em nossa consciência) e, de outro lado, a temporalidade de nosso corpo, que não retém nada além de seu passado imediato.

\footnotetext{
${ }^{7}$ Como ressalta a esse respeito Frédéric Worms: "Eis que é a vida do corpo que não pode mais se pensar por ela mesma e que, já que ela supõe um ato mínimo de contração temporal e ela é 'já memória', integra-se à vida do espírito". (WORMS, 2004, p. 164). Tradução nossa.
} 


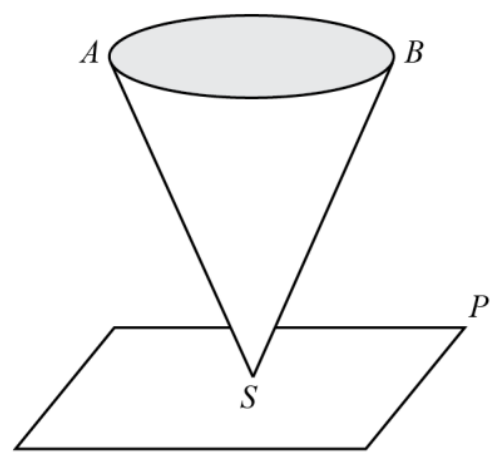

Figura 2 - O cone invertido ${ }^{8}$

As duas memórias não estão, portanto, numa relação de exclusão recíproca, mas de complementaridade, prestando-se ambas "um mútuo apoio" (BERGSON, 1999, p. 178), pois ambas fazem parte de uma mesma estrutura temporal. Segundo Bergson, é pelo equilíbrio entre ambas as memórias que reconhecemos "os homens perfeitamente adaptados à vida" (BERGSON, 1999, p. 179). Com efeito, diz o filósofo francês, o homem que vivesse no domínio da memória-hábito, isto é, no puro presente da ponta do cone, simplesmente reagindo corporalmente aos estímulos que recebe de seu meio ambiente, não seria senão um autômato espiritual, um homem impulsivo. Pelo contrário, um homem que vivesse simplesmente rememorando seu passado individual em seus mais mínimos detalhes, situando-se, portanto, na base do cone, seria apenas um sonhador. Entre ambos os extremos, contudo, temos o homem que se move constantemente entre a memória espontânea e a memória-hábito, entre o polo da vida espiritual e o da vida corporal. Esse é, para Bergson, o homem dotado de bom senso, ou seja, da capacidade de tornar materialmente efetivo aquilo que é do domínio da idealidade, da imaginação e da memória. "O bom senso, ou senso prático, não é na verdade outra coisa" (BERGSON, 1999, p. 179).

Compreendemos a partir disso como se dá a relação entre o corpo e o espírito para Bergson: não há para ele uma relação de exclusão entre os dois, mas de complementaridade, na medida em que ambos são diferentes graus de duração, diferentes graus de contração do passado. Como Bergson coloca de forma pungente no primeiro capítulo de Matéria e

\footnotetext{
${ }^{8}$ Eis o texto explicativo do próprio Bergson: "Se eu representar com um cone SAB a totalidade das lembranças acumuladas em minha memória, a base $\mathrm{AB}$, assentada no passado, permanece imóvel, enquanto o vértice $\mathrm{S}$, que figura a todo momento meu presente, avança sem cessar, e sem cessar também toca o plano móvel P de minha representação atual do universo. Em S concentra-se a imagem do corpo; e, fazendo parte do plano $\mathrm{P}$, essa imagem limita-se a receber e a devolver as ações emanadas de todas as imagens de que se compõe o plano". (BERGSON, 1999, p. 177-8).
} 
memória: "as questões relativas ao sujeito e ao objeto, à sua distinção e à sua união, devem ser colocadas mais em função do tempo que do espaço" (BERGSON, 1999, p. 75). No caso específico que nos ocupa, isso implica dizer que jamais conseguiremos esclarecer a questão da união entre a mente e o corpo se nos mantivermos num paradigma espacializante, que pensa essa união como a relação entre um "dentro" e um "fora", ou entre um continente e um conteúdo. Para Bergson essa união só pode ser pensada em termos temporais, e o problema filosófico da relação mente-corpo só pode ser resolvido a partir do momento em que compreendemos que ambos, o corpo e o espírito, não são senão graus diferentes de duração de uma mesma estrutura temporal. Um dos aspectos mais revolucionários da teoria dos graus de duração bergsoniana consiste, sem dúvida, em oferecer uma solução ao mesmo tempo simples e elegante a um clássico problema filosófico.

\section{A formação das ideias gerais}

Um aspecto que não pode ser esquecido no terceiro capítulo de Matéria e memória, contudo, é que Bergson está preocupado não apenas em explicar como se dá a relação entre a mente e o corpo, mas também o mecanismo mais amplo de formação da ideia geral, ao qual ele consagra um grande número de páginas. De fato, para o filósofo francês, o mesmo esquema que explica o modo de relação entre a mente e o corpo serve para explicar o modo de formação das ideias gerais. É sobre ele que nos deteremos a partir de agora.

Como vimos, as duas memórias discriminadas por Bergson (a memória-hábito e a memória espontânea), por mais que sejam complementares, diferem entre si profundamente. No que tange à problemática da ideia geral, Bergson dirá que, por um lado, a memória espontânea, na medida em que contrai a totalidade de nossa existência passada, nos dá acesso a uma multidão de lembranças absolutamente particularizadas, que têm como característica fundamental diferir umas das outras. Por outro lado, a memória-hábito, instalada no presente e retendo apenas nosso passado imediato, busca numa determinada situação somente aquilo que se assemelha a uma situação anterior, como vimos no caso do reconhecimento corporal. Ou seja, uma nos dá, por um lado, o diferente e o singular, a outra, o semelhante e o geral. Diremos, portanto, que uma das memórias é responsável pela formação das ideias gerais, enquanto a outra nos dá acesso aos objetos singulares? Na verdade, a situação é mais complexa do que isso, já que a ideia geral se forma, para Bergson, na confluência das duas 
memórias, envolvendo toda a diversidade de graus de duração vista anteriormente. Procuremos compreender como isso ocorre.

Bergson inicia sua análise assinalando que, historicamente, duas correntes opostas de pensamento se debateram acerca do problema da formação e do modo de ser das ideias gerais: o conceitualismo e o nominalismo ${ }^{9}$. Aqui, importa menos retraçar a crítica que Bergson efetua a ambas as doutrinas (que é, na verdade, muito sucinta e esquemática) do que apontar o erro mais geral no qual, para o filósofo, ambas as doutrinas incorrem, a saber, o de partir do postulado de que nossa percepção é primordialmente uma apreensão de objetos particulares: "Se aprofundássemos agora essas duas teorias adversárias, descobriríamos nelas um postulado comum: ambas supõem que partimos [no processo de conhecimento] da percepção de objetos individuais" (BERGSON, 1999, p. 185). Será esse postulado comum a ambas as doutrinas que Bergson buscará refutar. Para tanto, Bergson começa pontuando que a discriminação de espécies e gêneros envolve evolutivamente um certo "refinamento da inteligência", sendo um "privilégio do homem e de animais superiores" (BERGSON, 1999, p. 185). Segundo o filósofo francês, aquilo que ocorre com a discriminação das espécies e dos gêneros, ocorre também no caso da apreensão dos objetos particulares pela percepção, pois esta seria decorrente de um desenvolvimento evolutivo do qual não encontramos nenhum vestígio nos organismos mais primitivos. Lembremo-nos a esse respeito que, para Bergson, o objeto de nossa percepção somente pode se individualizar na medida em que projetamos uma lembrança particular sobre ele (como vimos no exemplo do poema “Tabacaria”). Ou seja, é somente a partir da intervenção da memória espontânea que a nossa percepção, a princípio completamente geral, pode se tornar uma percepção de objetos particularizados. Nada indica, contudo, que esse tipo de desenvolvimento da memória espontânea encontre-se em formas de vida menos evoluídas. A percepção de um animal é, antes de tudo, uma apreensão seletiva daquilo que é útil para ele, ou seja, uma percepção que descarta tudo aquilo que não caia na esfera do interesse imediato do organismo e que negligencia, portanto, tudo aquilo que um

\footnotetext{
${ }^{9}$ É importante distinguir aqui o conceitualismo e o universalismo (ou realismo exagerado). Na Idade média, o conceitualismo distinguia-se do universalismo por afirmar que os universais existem "post rem, ou seja, na mente, como conceitos abstratos", ao passo que o universalismo defendia que os universais existem "ante rem, isto é, antes das coisas sensíveis (ou seja, existem em si e por si)" (REALE, 2005, p. 171). Como pontua Camille Riquier na edição crítica de Matéria e memória, "ao privilegiar a oposição entre o nominalismo e o conceitualismo, antes que entre nominalismo e realismo, Bergson quer resolver o problema das ideias gerais sobre o plano psicológico, pelo estudo da vida geral do espírito.” (BERGSON, 2010, p. 391. Tradução nossa.) Não se trata, portanto, de reeditar a antiga querela sobre a existência independente ou não dos universais, mas de saber como eles se constituem no interior do espírito humano.
} 
objeto possa ter de individual ou singular, para ater-se somente ao que ele possui de comum com outros objetos semelhantes. Como afirma Bergson:

\begin{abstract}
A percepção dos animais costuma limitar-se a esse discernimento do útil. É o capim em geral que atrai o herbívoro: a cor e o odor do capim, sentidos e experimentados como forças (não chegamos ao ponto de dizer: pensados como qualidades ou gêneros), são os únicos dados imediatos de sua percepção exterior. Sobre este fundo de generalidade ou semelhança, sua memória poderá fazer valer os contrastes dos quais surgirão as diferenciações: ele distinguirá uma paisagem de outra paisagem, um campo de outro campo; mas isto, repetimos, é o supérfluo da percepção, e não o necessário. (BERGSON, 1999, p. 186).
\end{abstract}

Vemos aqui como Bergson inverte os termos habituais com os quais estamos acostumados a pensar; em quase toda a história da Filosofia, parte-se do pressuposto de que a percepção nos dá uma variedade de objetos particulares, com base nos quais nossa inteligência forma suas ideias gerais. Bergson defende exatamente o oposto: na verdade, partimos de uma generalidade vaga, dada na percepção, na qual nossa memória insere suas diferenças, particularizando progressivamente o conteúdo percebido. $\mathrm{Na}$ ordem do conhecimento, não vamos, portanto, do particular ao universal, mas do geral ao particular.

Mas aqui alguém poderia lançar algumas objeções: como é possível que a percepção seja geral logo a princípio? A generalidade não pressupõe que tenhamos primeiramente uma diversidade de objetos particulares, a partir da qual nós abstraímos o que há de semelhante entre eles, a fim de chegar a uma ideia geral que subsuma essa diversidade de particulares? A resposta de Bergson a essas objeções consiste em afirmar que essa generalidade da percepção não envolve nenhuma abstração, nenhum esforço de ordem intelectual, já que, antes de ser concebida, ela é vivida. O que isso significa fica mais claro quando nos debruçamos sobre o modo como o organismo apreende o ambiente ao seu redor. O nosso corpo, lembremo-nos, é para o filósofo francês um sistema sensório-motor, isto é, um sistema que apreende o ambiente sob a forma de sensações elementares, reagindo a ele por meio de sua ação motora. Ora, quando nos debruçamos sobre as sensações que o organismo forma a partir de seu entorno, percebemos que elas são, sem dúvida, bastante instáveis e variáveis. Mas a resposta motora que o organismo efetua a partir destas sensações é, por sua vez, quase sempre invariável: dadas as mesmas condições, um organismo tenderá a reagir de modo idêntico ao que agiu em situações passadas - assim, um animal que percebe uma presa buscará caçá-la, aquele que percebe uma ameaça tenderá a fugir etc. Mais do que isso, na grande maioria dos casos, os estímulos exteriores que recebemos não produzem nenhuma reação motora do organismo, permanecendo então indiferente ao que se passa ao seu redor. Desse modo, ele 
descarta tudo o que poderia haver de infinitamente rico e variado na sensação, para ater-se somente ao que lhe pode ser de alguma utilidade prática, ou seja, ao que há de comum entre a situação presente e outras situações passadas com as quais ele se defrontou. Sua percepção partirá assim antes de uma apreensão do geral e do semelhante do que do particular e do diferente, e isso sem que se pressuponha nenhum esforço de abstração, pois o que está em jogo é a simples identidade e constância dos estímulos e das respostas motoras do organismo ao longo do tempo.

Bergson esclarece que essa generalidade vaga da qual parte a percepção de qualquer ser vivo é o germe daquilo que será a universalidade de fato, que se desenvolve somente no caso do intelecto humano, e que está na origem de nossas ideias gerais, isto é, dos gêneros e das espécies. Como se dá esta passagem de uma generalidade meramente vivida a uma universalidade "inteligentemente percebida ou pensada"? (BERGSON, 1999, p. 188). Para Bergson, essa operação envolve basicamente uma reflexão da inteligência sobre a percepção, a qual leva à construção de um grande número de "aparelhos motores, desta vez artificiais, para fazê-los responder, em número limitado, a uma quantidade ilimitada de objetos individuais: o conjunto desses mecanismos é a palavra articulada" (BERGSON, 1999, p. 189). Portanto, ao contrário da generalidade sentida ou vivida pelos animais, que repousa no automatismo de suas reações corporais, a universalidade forjada pelo ser humano deriva da possibilidade de referir uma diversidade de objetos individuais a um signo artificialmente construído, a saber, a palavra falada. A capacidade de falar estaria, portanto, na origem da capacidade de real universalização presente no ser humano, e relativamente ausente nos demais animais. Até aqui, parece que Bergson segue uma visão das ideias gerais bem próxima daquela da tradição nominalista, na medida em que propõe que a universalidade de uma ideia deriva da simples aplicação de um único signo a um conjunto de coisas e ideias de extensão variável. Porém, na verdade, a questão é bem mais complexa, pois a ideia geral não se resume, para Bergson, à simples universalidade da palavra articulada, mas põe em jogo toda uma dinâmica entre as duas memórias que discriminamos anteriormente, a saber, a memória espontânea e a memória hábito. Para compreender como se dá esta dinâmica da ideia geral, Bergson retoma o gráfico do cone anteriormente proposto, com algumas pequenas modificações: 


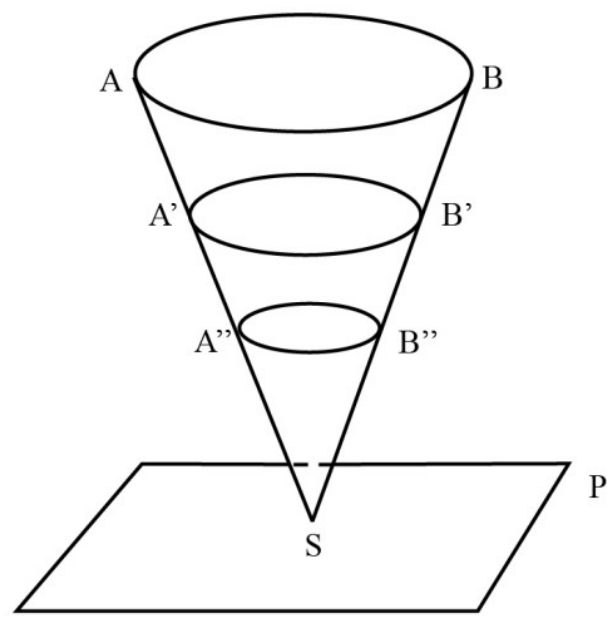

Figura 3 - Os graus de duração

Temos nesse gráfico a mesma base $\mathrm{AB}$ que representava, no gráfico anterior do cone, a totalidade das lembranças particulares retidas na memória espontânea. Do mesmo modo, temos aí a ponta $\mathrm{S}$, que representa "a percepção atual que tenho de meu corpo, ou seja, de um certo equilíbrio sensório-motor" (BERGSON, 1999, p. 189). Essa percepção atual do corpo, acrescenta Bergson, toma por sua vez "a forma bem nítida de uma atitude corporal ou de uma palavra pronunciada" (BERGSON, 1999, p. 189). Onde se encontra a ideia geral neste esquema proposto por Bergson? Para ele, a ideia geral não se deixa resumir a nenhuma das extremidades do cone, mas "consiste na dupla corrente que vai de uma à outra [extremidade] - sempre pronta, seja a cristalizar-se em palavras pronunciadas, seja a evaporar-se em lembranças" (BERGSON, 1999, p. 189).

Como já dissemos antes, poderíamos achar que Bergson se aproxima aqui de uma certa concepção nominalista, já que ele defenderia que a ideia geral surge quando um certo número de lembranças particulares é relacionado a uma determinada palavra falada, isto é, quando ligamos determinados elementos da base $\mathrm{AB}$ à ponta $\mathrm{S}$. De fato, a situação é um pouco mais complexa, pois além da base $A B$, temos também as seções A'B', A'B' do cone etc. que correspondem, segundo Bergson "a milhares e milhares de repetições de nossa vida psicológica" (BERGSON, 1999, p. 190). Segundo o filósofo francês, estas repetições, que correspondem aos diversos círculos da memória que vimos anteriormente, correspondem a formas mais ou menos contraídas de nossa memória espontânea, que se condensa integralmente em cada um destes círculos, mas adotando em cada um deles uma forma mais 
impessoal e ordinária. O que isso significa exatamente? O problema que preocupa Bergson a essa altura de Matéria e memória é saber como se formam as ideias gerais, que se organizam numa diversidade hierarquizada de gêneros e espécies, e vão desde o mais geral até o mais particular. Como vimos, a base e a ponta do cone nos dão, por um lado, uma diversidade de lembranças individualizadas, completamente diferentes entre si; por outro lado, um signo qualquer, que pode ser aplicado indiscriminadamente a um único indivíduo ou a uma multidão deles. Eles não explicam, contudo, como pode haver uma hierarquia bem determinada de espécies e gêneros. O que falta a Bergson explicar ao seu leitor é como se dá a consolidação da ideia geral numa diversidade de espécies e gêneros bem determinados, em que um engloba o outro em graus diferentes de generalidade. É para responder a essa pergunta bem precisa que ele propõe essa diversidade de seções do cone, de repetições de nossa vida psíquica. Embora Bergson não seja totalmente claro a esse respeito, parece bastante evidente que ele pensa que, em cada uma destas seções, as lembranças da seção precedente se fundem entre si, formando uma espécie que engloba os elementos da seção precedente. Teríamos assim, entre as diversas seções, uma estrutura de gêneros e espécies bem determinada, fundada nessa capacidade de "expansão" e "contração" de nossa memória espontânea. Retomando nosso exemplo anterior: na base do cone AB, temos as lembranças individuais, entre os quais se inclui a leitura de um poema determinado numa ocasião específica (por ex., o poema “Tabacaria”). Na seção seguinte A'B', essa mesma lembrança aparece fundida com outras lembranças semelhantes, compondo uma espécie que engloba os diversos elementos da seção precedente, formando a ideia geral de "poema". Por sua vez, na seção seguinte A'’B', teríamos uma fusão das lembranças dos diversos gêneros textuais na ideia geral de "texto". E, por fim, ao alcançar a ponta $\mathrm{S}$, teríamos a enunciação dessa ideia geral por meio de um signo arbitrariamente escolhido, que poderia designar qualquer um dos elementos acima ("Tabacaria", "poema", "texto"). Desse modo, vemos que Bergson se recusa a adotar um nominalismo simples, uma vez que ele crê que há um fundamento psicológico bem determinado por trás da formação das ideias gerais, o qual pode dar conta, segundo ele, de nossa hierarquia habitual de gêneros e espécies. Tudo depende aqui do grau de tensão ou de intensidade atingido por nossa consciência, o qual lhe permite situar-se num determinado grau de expansão ou contração do passado - isso equivale a dizer, num certo grau de individualidade de seu objeto.

Compreendemos agora como a teoria dos planos de consciência, que buscava dar conta das relações entre o corpo e o espírito, busca também explicar o modo de formação das 
ideias gerais. De fato, na medida em que busca dar conta da formação de nossas percepções concretas, de nossas lembranças e de nossos conceitos, a teoria dos graus de duração permite a formulação de uma pequena teoria do conhecimento, a qual está fundamentada, por sua vez, na relação profunda entre o presente e o passado puro, entre o atual e o virtual.

\section{Conclusão}

Buscamos mostrar, ao longo deste artigo, a relação que Bergson estabelece entre, de um lado, a memória espontânea, e de outro, a formação de nossas ideias gerais e de nossas percepções concretas. Como tentamos caracterizar, esta relação equivale, no fundo, ao esboço de uma incipiente teoria do conhecimento calcada na ideia bergsoniana de que existe uma diversidade de planos de consciência ou graus de duração. Se nosso ponto de vista está correto, então a memória desempenha um papel fundamental, seja na estruturação de nossa sensibilidade, seja de nosso intelecto. Como dizíamos no início deste artigo, a memória não é para Bergson uma faculdade como as demais, mas a condição de possibilidade de todas as faculdades. Por um lado, o filósofo afirma que "é a lembrança que nos faz ver e ouvir" (BERGSON, 2009, p. 170), ou seja, que a memória é a condição de base de toda a nossa sensibilidade, por outro lado, ele afirma que é a rememoração do passado, em seus diversos níveis possíveis de atualização, que possibilita a formação das ideias gerais. Sem a memória, não haveria, portanto, um exercício possível da sensibilidade, nem sequer do intelecto. Compreendemos mais uma vez, a partir disso, porque Bergson afirma que "consciência significa primeiramente memória" (BERGSON, 2009, p. 5). Isso se dá não apenas porque todo estado consciente envolve uma retenção do passado no presente, mas também porque o passado está sendo constantemente rememorado e atualizado no presente, em diversos graus ou níveis possíveis: são estes, basicamente, os dois modos pelas quais a memória contribui e torna possíveis as diversas formas de conhecimento.

\section{REFERÊNCIAS BIBLIOGRÁFICAS}

BERGSON, H. Essai sur les données immédiates de la conscience (édition critique). Paris: PUF, 2011. . Matéria e memória. São Paulo: Martins Fontes, 1999. . Matière et mémoire (édition critique). Paris: PUF, 2010. 
. A energia espiritual. São Paulo: Martins Fontes, 2009.

. O pensamento e o movente. São Paulo: Martins Fontes, 2006.

COELHO, J. A crítica bergsoniana do conhecimento. Mimesis, Bauru, v.22, n.2, p. 07-24, 2001.

DELEUZE, G. Bergsonismo. São Paulo: Editora 34, 2004.

LEOPOLDO E SILVA, F. Bergson: intuição e discurso filosófico. São Paulo : Edições Loyola, 1994.

MARQUES, S. Ser, tempo e liberdade: as dimensões da ação livre na filosofia de Henri Bergson. São Paulo: FAPESP, 2006.

PRADO Jr., B. Presença e campo transcendental - consciência e negatividade na Filosofia de Bergson. São Paulo: EDUSP, 1989.

REALE, G. ANTISERI, D. História da filosofia: patrística e escolástica, vol, 2. São Paulo: Paulus, 2005.

RIQUIER, C. Archéologie de Bergson : temps et métaphysique. Paris : PUF, 2009.

WORMS, F. Introduction à Matière et mémoire de Bergson. Paris: PUF, 1997.

. La théorie bergsonienne de plans de conscience: genèse, structure et signification de Matière et mémoire. In: GALLOIS, P. FORZY, G. Bergson et les neurosciences. Le Plessis Robinson: InstitutSynthélabo, 1997B. p. 85-108.

. Bergson ou les deux sens de la vie. Paris: PUF, 2004. 